\title{
Kinesin family members KIF11 and KIF23 as potential therapeutic targets in malignant pleural mesothelioma
}

\author{
TATSUYA KATO ${ }^{1,2}$, DAIYOON LEE ${ }^{1}$, LICUN WU $^{1}$, PRIYA PATEL ${ }^{1}$, AHN JIN YOUNG $^{1}$, \\ HIRONOBU WADA ${ }^{1}$, HSIN-PEI HU ${ }^{1}$, HIDEKI UJIIE ${ }^{1}$, MITSUHITO KAJI ${ }^{3}$, SATOSHI KANO ${ }^{4}$, \\ SHINICHI MATSUGE ${ }^{5}$, HIROMITSU DOMEN ${ }^{2}$, KICHIZO KAGA $^{2}$, YOSHIRO MATSUI $^{2}$, HIROMI KANNO $^{6}$, \\ YUTAKA HATANAKA $^{6}$, KANAKO C. HATANAKA $^{6}$, YOSHIHIRO MATSUNO ${ }^{6}$, \\ MARC DE PERROT $^{1}$ and KAZUHIRO YASUFUKU ${ }^{1}$

\begin{abstract}
${ }^{1}$ Division of Thoracic Surgery, Toronto General Hospital, University Health Network, Toronto, Canada;
${ }^{2}$ Department of Cardiovascular and Thoracic Surgery, Hokkaido University Graduate School of Medicine, Sapporo;

${ }^{3}$ Department of Thoracic Surgery, Sapporo Minami-sanjo Hospital, Sapporo; Departments of ${ }^{4}$ Pathology and ${ }^{5}$ Surgery, Kinikyo-Chuo Hospital, Sapporo; ${ }^{6}$ Department of Surgical Pathology, Hokkaido University Hospital, Sapporo, Japan
\end{abstract}

Received December 15, 2015; Accepted January 20, 2016

DOI: $10.3892 /$ ijo.2016.3566

\begin{abstract}
Malignant pleural mesothelioma (MPM) is a rare and aggressive form of cancer commonly associated with asbestos exposure that stems from the thoracic mesothelium with high mortality rate. Currently, treatment options for MPM are limited, and new molecular targets for treatments are urgently needed. Using quantitative reverse transcription-polymerase chain reaction (RT-PCR) and an RNA interference-based screening, we screened two kinesin family members as potential therapeutic targets for MPM. Following in vitro investigation of the target silencing effects on MPM cells, a total of 53 MPMs were analyzed immunohistochemically with tissue microarray. KIF11 and KIF23 transcripts were found to be overexpressed in the majority of clinical MPM samples as well as human MPM cell lines as determined by quantitative RT-PCR. Gene knockdown in MPM cell lines identified growth inhibition following knockdown of KIF11 and KIF23. High expression of KIF11 (KIF11-H) and KIF23 (KIF23-H) were found in 43.4 and $50.9 \%$ of all the MPM cases, respectively. Patients who received curative resection with tumors displaying KIF23-H showed shorter overall survival $(\mathrm{P}=0.0194)$. These results provide that inhibition of KIF11 and KIF23 may hold promise for treatment of MPMs, raising the possibility that kinesin-based drug targets may be developed in the future.
\end{abstract}

Correspondence to: Dr Kazuhiro Yasufuku, Division of Thoracic Surgery, Toronto General Hospital, University Health Network 200 Elizabeth Street, 9N-957, Toronto, ON M5G2C4, Canada

E-mail: kazuhiro.yasufuku@uhn.ca

Key words: KIF11 (Eg5), KIF23 (MKLP1), therapeutic target genes, immunohistochemistry, malignant pleural mesothelioma

\section{Introduction}

Malignant pleural mesothelioma (MPM) is a rare but aggressive tumor that arises from mesothelial cells lining the pleural cavities, and is linked to exposure to carcinogenic asbestos, and its worldwide incidence continues to increase (1). It will continue to be a global health concern in the next few decades due to the continued use of asbestos in developing countries $(1,2)$. Depending on different etiologies of the disease, MPM can be divided into four types: epithelioid, sarcomatoid, desmoplastic and biphasic, according to the World Health Organization (WHO) classification of pleural tumors (3). MPM has an extremely poor prognosis, and the median survival time for the main three types (epithelioid, sarcomatoid and biphasic) is 18, 8 and 11 months, respectively and current treatment strategies are limited (4-6). Aggressive surgery, screening with proposed biomarkers, advances in modern systemic chemotherapy, and combination of radiotherapy and chemotherapy regimens are currently being tested, but their benefits of these treatments are unclear at this time, and long-term survival in patients with MPM is still rare $(7,8)$. The lack of major improvements in the survival rate has facilitated research into identifying new strategies aimed at improving MPM survival. To improve these survival rates, more specific, effective and less toxic therapies are needed. Investigating molecular analyses of MPM samples has led to novel targeted strategies that inhibit specific key molecules in tumor growth and progression.

We have been attempting to isolate potential molecular targets for diagnosis and/or treatment of advanced lung cancer (9) and malignant mesothelioma by analyzing gene expressions using real-time reverse-transcriptase polymerase chain reaction (RT-PCR) based on profiles of various types of database, NCBI-Gene ${ }^{\circledR}(10)$, GeneCards $^{\circledR}(11)$, GenomeRNAi $^{\circledR}$ (12) and CTDatabase $^{\circledR}$ (13). Throughout these screenings, we identified two kinesin family members: kinesin family member 11 (KIF11; alias EG5) and kinesin family member 23 (KIF23; 
Table I. Patient and tumor characteristics.

\begin{tabular}{lc}
\hline Variables & $\mathrm{n}(\%)$ \\
\hline Gender (Male/female) & $49 / 4(92.5 / 7.5)$ \\
Age (years) (mean) & 65.5 \\
& (range, $35-80)$ \\
Histology & \\
Epithelioid type & $34(64.2)$ \\
Biphasic type & $13(24.5)$ \\
Sarcomatoid type & $5(9.4)$ \\
Desmoplastic type & $1(1.9)$ \\
Surgical procedure & \\
Extrapleural pleuropneumonectomy (EPP) & $21(39.6)$ \\
Pleural biopsy & $28(52.8)$ \\
Recurrent tumor resection & $3(5.7)$ \\
Radical pleurectomy & $1(1.9)$ \\
Total & 53 \\
\hline
\end{tabular}

alias KNSL5; MKLP1), as potential candidate target genes for the treatment of MPMs.

The aims of the present study were to examine the frequency of transcriptional expression of these target genes in MPM samples, to investigate its functional role in MPM cell proliferation by using an RNA interference (RNAi) technique, to assess clinicopathological relationships in MPM by immunohistochemistry (IHC) using tissue microarray (TMA), and to explore the possibilities of these target genes as a potential molecular target for therapeutic agents.

\section{Materials and methods}

Malignant mesothelioma clinical samples and tissue samples. Thirteen samples were obtained from patients with MPMs, including subtypes of 6 epithelioids, 6 biphasics and 1 sarcomatoid, with written informed consent at Toronto General Hospital (Toronto, Canada). For TMA analysis, a total of 53 MPM were obtained from patients who underwent surgery at Hokkaido University Hospital and its affiliated hospital between February 1990 and April 2012. Patient's clinical information was extracted from the medical records. The protocol was approved by the appropriate institutional review board of Hokkaido University (no. 012-0136). Detailed information about demography, clinical characteristics and pathological stage are summarized in Table I. Postoperative pathological staging evaluation was demonstrated only in curative operative cases $(n=21)$, showing stage I disease in 1 case, stage II disease in 5 cases, and stage III disease in 15 cases. In all, 1 patient had T1 disease, 7 patients had T2 disease and 13 patients had T3 disease. A total of 9 patients had N0 disease, 5 patients had N1 disease and 7 patients had N2 disease. Histological classification of tumors and stage were performed according to the Union for International Cancer Control (UICC) pathological tumor/node/metastasis (pTNM) classification criteria (14).
Malignant mesothelioma cell lines. The human malignant mesothelioma cell lines used in the present study were as follows: NCI-H28, -H226, -H2052 and -H2452 were purchased from the ATCC (Manassas, VA, USA). All cancer cells were grown in monolayers in RPMI-1640 medium supplemented with $10 \%$ fetal bovine serum (FBS). A human adult normal mesothelial cell line (MES-F) was purchased from Zimbio Inc. (Research Triangle Park, NC, USA) and was grown in mesothelial cell growth medium (Zimbio). All cell lines were maintained at $37^{\circ} \mathrm{C}$ in atmospheres of humidified air with $5 \% \mathrm{CO}_{2}$.

cDNA sample preparation. Tumor samples from MPM patients with surgery were excised and stored at $-80^{\circ} \mathrm{C}$. QIAzol lysis reagent (Qiagen, Valencia, CA, USA) and one 5-mm stainless steel Bead (Qiagen) were added before homogenizing with a TissueLyser Adapter Set (Qiagen) for $2 \mathrm{~min}$ at $20 \mathrm{~Hz}$ $(15,16)$. Total RNA was then purified using a miRNeasy Mini kit (Qiagen). The amount and purity were measured using a spectrophotometer (NanoDrop; Thermo Fisher Scientific, Wilmington, DE, USA).

Quantitative RT-PCR analysis. cDNA was synthesized from $1 \mu \mathrm{g}$ total RNA using QuantiTect ${ }^{\circledR}$ Reverse Transcription kit (Qiagen). The primers were designed as follows: for KIF11, forward primer, 5'-acagcctgagctgttaatgatg-3' and reverse, 5'-gatggctcttgacttagaggttc-3'; for KIF23, forward primer, 5'-tg gttcctacattcagaaatgaga-3' and reverse, 5'-cgttctgatcaggttga aagagta-3'; for actin, beta (ACTB), forward primer, 5'-gaaat cgtgcgtgacattaa-3' and reverse, 5'-aaggaaggctggaagagtg-3'; Quantitative RT-PCR analysis was performed using the LightCycler $480{ }^{\circledR}$ SYBR-Green I Master Ready-to-use hot start reaction mix and LightCycler $480{ }^{\circledR}$ system (Roche, South San Francisco, CA, USA). The thermal cycler conditions were as follows: $5 \mathrm{~min}$ at $95^{\circ} \mathrm{C}$ for denaturation, 45 cycles at $95^{\circ} \mathrm{C}$ for $10 \mathrm{sec}, 56^{\circ} \mathrm{C}$ for $20 \mathrm{sec}$, and $72^{\circ} \mathrm{C}$ for $10 \mathrm{sec}$ for PCR amplification, and $1 \mathrm{~min}$ at $65^{\circ} \mathrm{C}$ for melting. The threshold cycle value was defined as the value obtained in the PCR cycle when the fluorescence signal increased above the background threshold. PCR reactions were carried out in duplicates.

RNA interference and cell viability assay. All short interference RNA (siRNA) oligonucleotide sequences for KIF11 and KIF23 siRNAs were purchased from Qiagen for the present study. AllStar Negative Control siRNA ${ }^{\circledR}$ (Qiagen) were used as the negative control (NC-siRNA). The final concentration of $10 \mathrm{nM}$ of siRNAs was incubated with HiPerFect ${ }^{\circledR}$ transfection reagent (Qiagen) according to the manufacturer's instructions. The CellTiter96 ${ }^{\circledR}$ AQueous One Solution Cell Proliferation Assay (Promega, Madison, WI, USA) was used for the evaluation of the number of viable cells according to the manufacturer's instructions, using a microplate spectrophotometer ( $\mu$ Quant; BioTek Instruments, Inc., Winooski, VT, USA). Each experiment was performed in triplicates.

Tissue microarray construction and immunohistochemistry. Archival slides for all the cases were reviewed to select three representative areas for each sample by an experienced pathologist (K.H.). TMA blocks were then constructed using a manual tissue microarrayer (JF-4; Sakura Finetek Japan Co., Ltd., Tokyo, Japan) with a $1.0-\mathrm{mm}$ diameter needle. The 
finalized array blocks were sliced into $4-\mu \mathrm{m}$-thick sections and mounted on glass slides. To check the histopathological diagnosis and adequacy of tissue sampling, a section from each TMA was stained with regular hematoxylin and eosin (H\&E), as well as calretinin immunohistochemistry (IHC), and examined by the same pathologist (K.H.). For KIF23 immunostaining, deparaffinization, antigen retrieval and IHC were performed on paraffin-embedded TMA sections and on whole sections using an automated IHC platform (Bond Max ${ }^{\mathrm{TM}}$; Leica Microsystems, Newcastle, UK). Antigen retrieval was performed in the condition of $\mathrm{pH} 6.0$ for $20 \mathrm{~min}$ The detection kit used was the Bond Polymer Refine Detection (DS9800; Leica Microsystems), incubation with post-primary for $20 \mathrm{~min}, 3$ times at room temperature (RT). Anti-KIF23 monoclonal antibody [MKLP-1 (H-110): sc-22793; Santa Cruz Biotechnology, Santa Cruz, CA, USA; 1/100] was diluted using mixed antibody diluent (Dako:X0909 Protein Block SerumFree: Dako:S0809 antibody diluent: Nichirei 10\% normal goat serum 1:1:1). A polymer-based detection system (Refine cat. \#DS9800) was used with 3',3-diaminobenzidine (DAB) as the chromogen. The positive controls included a sample of testis and the negative control was performed on all cases by the rabbit primary antibody (Dako:X0903, rabbit immunoglobulin fraction (normal)]. KIF11 immunostaining were performed using an automated IHC platform (Autostainer plus; Dako, Glostrup, Denmark). Antigen retrieval was performed at pH 9.0 for 20 min. The detection kit used was the EnVision ${ }^{\mathrm{TM}}+$ Dual Link (K4063; Dako), incubation with post-primary for 60 min at RT. Anti-KIF11 polyclonal antibody (GTX109054; GeneTex, Inc., Irvine, CA, USA; 1:1,500) was diluted using mixed antibody diluent (Dako S2022 antibody diluent). A polymer-based detection system $\left(\right.$ EnVision $^{\mathrm{TM}}+$ Dual Link \#K4063) was used with 3',3-diaminobenzidine (DAB) as the chromogen. The positive controls included a sample of testis, and normal lung and normal pleural samples were used as negative controls. Slides were dehydrated and placed on coverslips.

Evaluation of immunohistochemical staining and statistical analysis. Digital images of IHC-stained TMA slides including 53 MPM cases were obtained using a whole slide scanner (ScanScope CS, Aperio ePathology; Leica Microsystems Inc., Toronto, ON, Canada). Annotation of tumor regions on whole slides was performed blinded to clinical follow-up data using Aperio's annotation software (ImageScope Viewing software, positive pixel count ver. 9.1). KIF11 and KIF23 were quantified by IHC scoring, which summated the percentage of area stained at each intensity level multiplied by the weighted intensity ( $0,1,2$ or 3$)$ reported in other studies (17-19) (Fig. 3). Initially, the weighted intensity of staining was graded as follows; grade 0 (negative), $1+$ (weak positive), $2+$ (moderate positive), and $3+$ (strong positive) according to Aperio's annotation software). According to the total amount of IHC scores, KIF11 and KIF23 expression were then finally divided into two groups each (the threshold leading to the lowest P-value in log-rank test): low-level KIF11 expression (KIF11-L, with an IHC score $<0.7$ ) and high-level KIF11 expression (KIF11-H, with an IHC score $\geq 0.7$ ), and low-level KIF23 expression (KIF23-L, with an IHC score <0.4) and high-level KIF23 expression (KIF23-H, with an IHC score $\geq 0.4)$. We attempted to correlate clinicopathological variables such as age, gender, pathological TNM stage, and histological classification with expression levels of KIF11 and KIF23 protein as determined by TMA analysis. Immunoreactivity was assessed for association with clinicopathological variables using the Fisher's exact for variables. Kaplan-Meier method was used to generate survival curves, and survival differences were analyzed with the logrank test, based on the status of KIF11 and KIF23 expression. Values of $\mathrm{P}<0.05$ were considered statistically significant. All analyses were performed using StatView version 5.0 software (SAS Institute, Inc., Cary, NC, USA).

\section{Results}

Expression of KIF11 and KIF23 transcripts in mesotheliomas and normal human tissues. By screening for molecular targeted genes as described above, we identified KIF11 and KIF23 overexpression with quantitative RT-PCR experiments in a majority of MPM cases (Fig. 1A). We also confirmed a high expression of these genes using 4 human MPM cell lines and low expression in a normal human mesothelial cell line (MES-F) (Fig. 1B). Quantitative PCR analysis using a cDNA panel containing normal human tissues also showed that these genes expressed mainly in the testis and thymus among different normal human organs examined (data not shown), which provides further evidence supporting these genes as promising molecular targets.

Growth inhibition of mesothelioma cells by specific siRNA against KIF11 and KIF23. To assess whether therapeutic candidate genes are essential for growth or survival of MPM cells, we transfected specific siRNAs against KIF11 (si-KIF11\#4, si-KIF11-\#6 and si-KIF11-\#8), KIF23 (si-KIF23-\#1, si-KIF23-\#8 and si-KIF23-\#9) into human MPM cell lines $\mathrm{H} 28$ and $\mathrm{H} 2052$, using AllStar siRNA ${ }^{\circledR}$ as the negative control (NC-siRNA). The mRNA levels of transfected cells with independent siRNAs targeting these genes were significantly decreased in comparison to cells transfected with control siRNAs $48 \mathrm{~h}$ after transfection (Fig. 2A). Next, to evaluate the relationship between cell proliferation and gene knockdown, we conducted a cell viability assay using the CellTiter $96^{\circledR}$ AQueous One Solution Cell Proliferation Assay. After siRNA treatment, proliferation of $\mathrm{H} 28$ and $\mathrm{H} 2052$ cells was significantly suppressed compared with control groups at day 4 after transfection (Fig. 2B), suggesting that upregulation of these candidate genes are related to growth or survival of MPM cells. Typical microscopic images of the cells are shown in Fig. 2C. Compared to control cells or control siRNA-treated cells, KIF11 siRNA-treated mesothelioma cells more frequently induced cell cycle arrest for mitotic cells with monopolar spindles called 'monoastral spindle' $(20,21)$. KIF23 siRNA-treated mesothelioma cells exhibited large cell bodies with two or more nuclei. Depletion of KIF23 induces the formation of 'multinucleate cells', likely because of a cytokinesis defect (22-24).

Pattern of KIF11 and KIF23 expression in MPMs and correlation to clinicopathological parameters and prognostic significance. We categorized KIF11 and KIF23 expression on the TMA according to the IHC score described above. Positive 
A
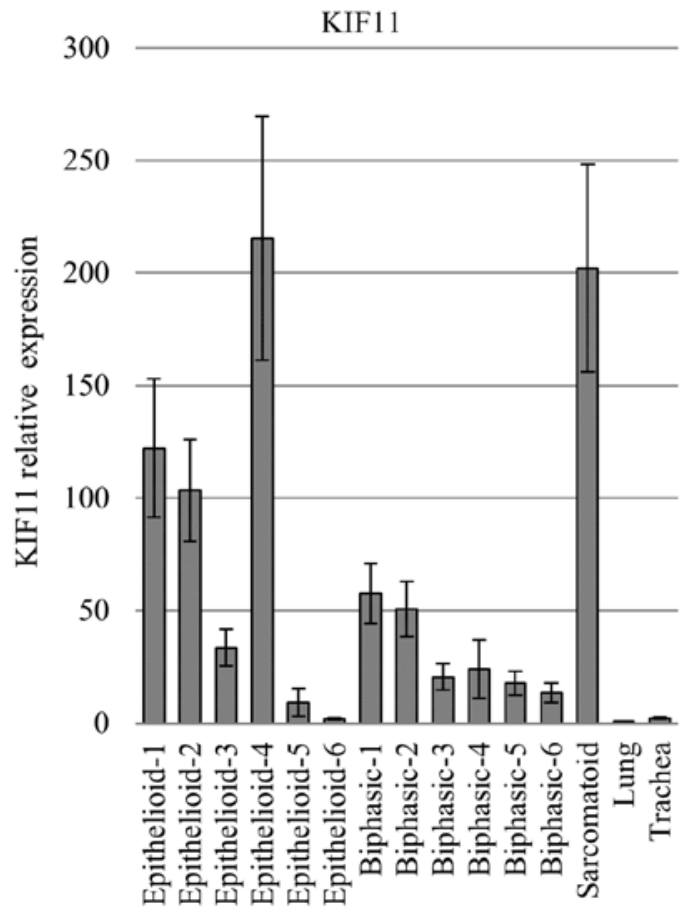

B

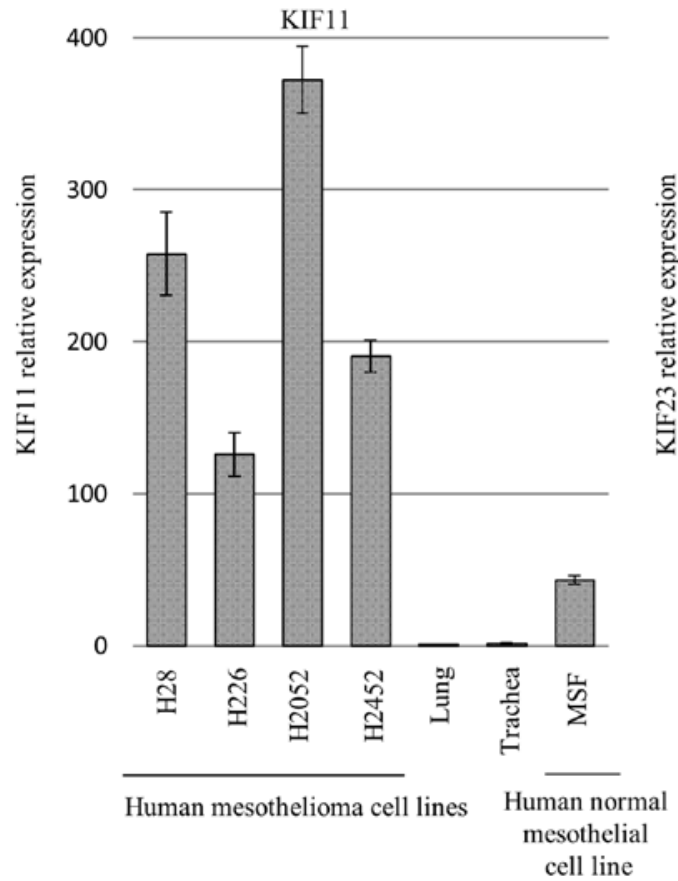

250 KIF23
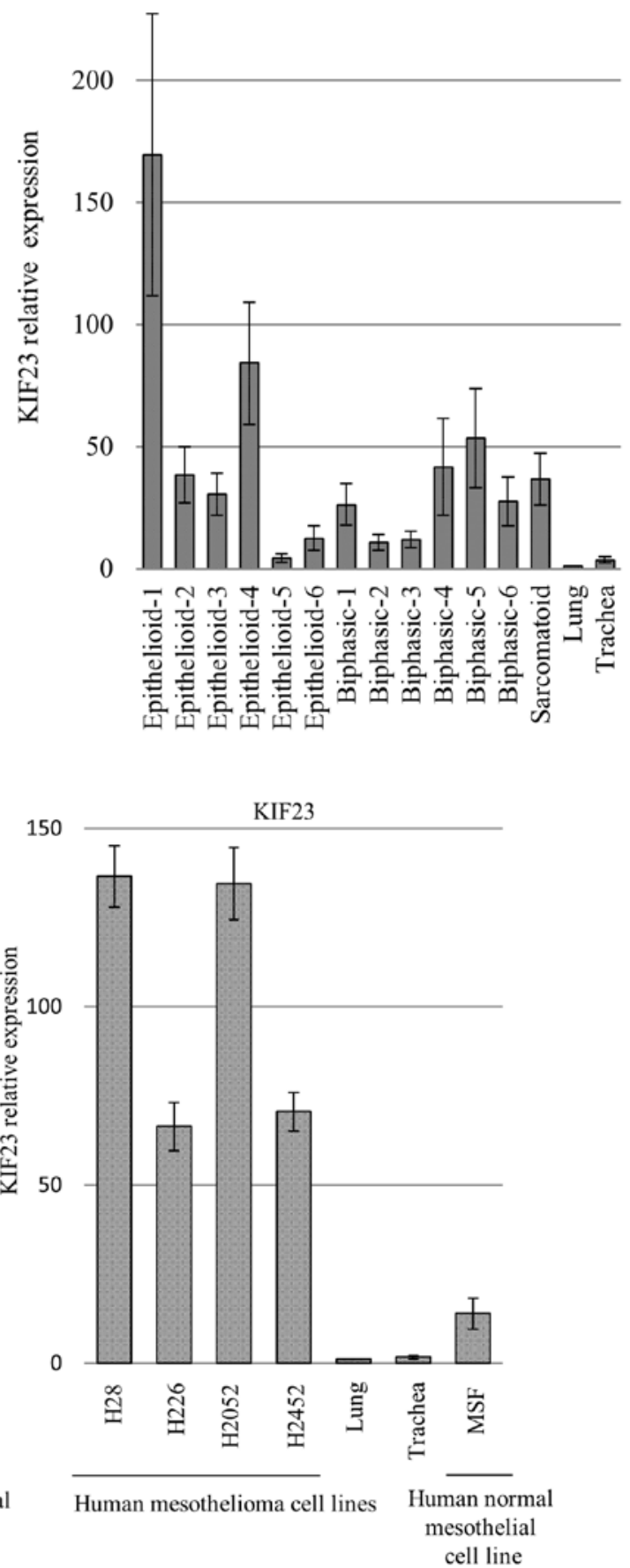

Figure 1. Expression of KIF11 and KIF23 in malignant pleural mesotheliomas (MPMs). (A) Expression of KIF11 and KIF23 genes in mesothelioma clinical samples. The relative gene expression level was normalized to the ACTB level in each sample and calculated as the threshold cycle (CT) value divided by the CT value in the normal lung. Bar represents the mean of duplicate. (B) Expression of these genes in human mesothelioma cell lines and a human normal mesothelial cell line (MES-F).

staining of tumor cells by KIF11 and KIF23 generally showed a cytoplasmic pattern in cancer tissue, and no staining was observed in benign chronic or fibrous pleuritis and normal lung tissues (Fig. 3B). Of the 53 malignant mesothelioma cases examined, KIF11-H was observed in 23 cases $(43.4 \%)$ and KIF23-H was observed in 27 cases $(50.9 \%$ ) (details are shown in Table II). Of those, 16 epithelioid type ( $47.1 \%$ of 34 cases), 6 biphasic type (46.2\% of 13 cases), and 1 sarcomatoid type (20.0\% of 5 cases) showed KIF11-H. Twenty-two epithelioid type (64.7\% of 34 cases), 5 biphasic type (38.5\% of 13 cases) expressed KIF23-H, but no KIF23-H case was found in sarcomatoid and desmoplastic type. We then tried to correlate KIF11 and KIF23 expression with various clinicopathological parameters. However, no significant association was noted between KIF11 and KIF23 expression and other clinicopathological variables in curative operative cases (data not 
A

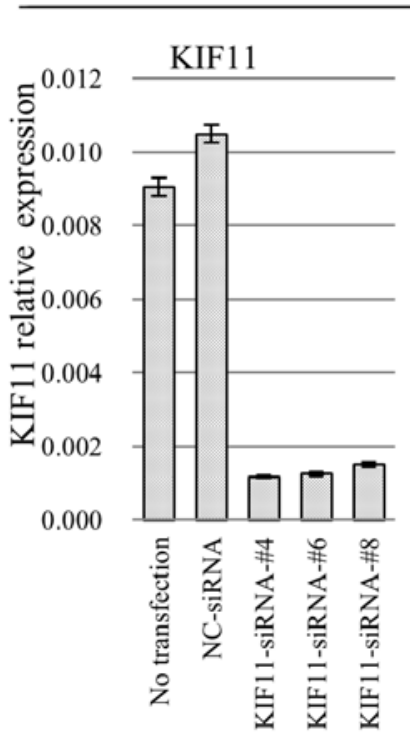

H28 cells

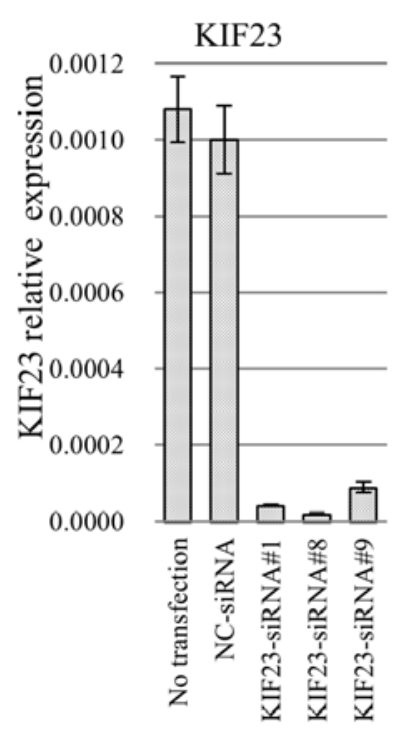

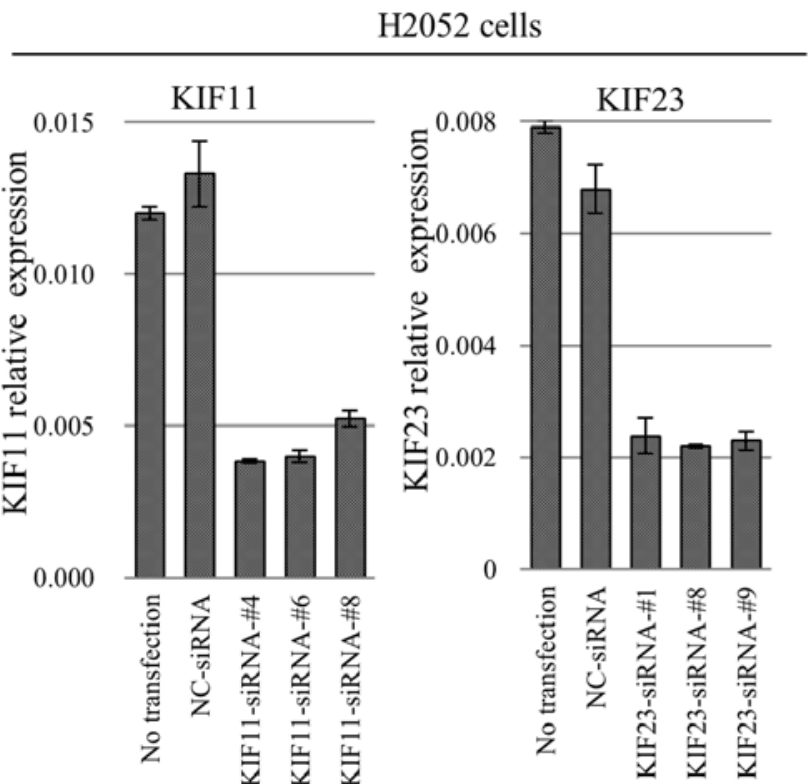
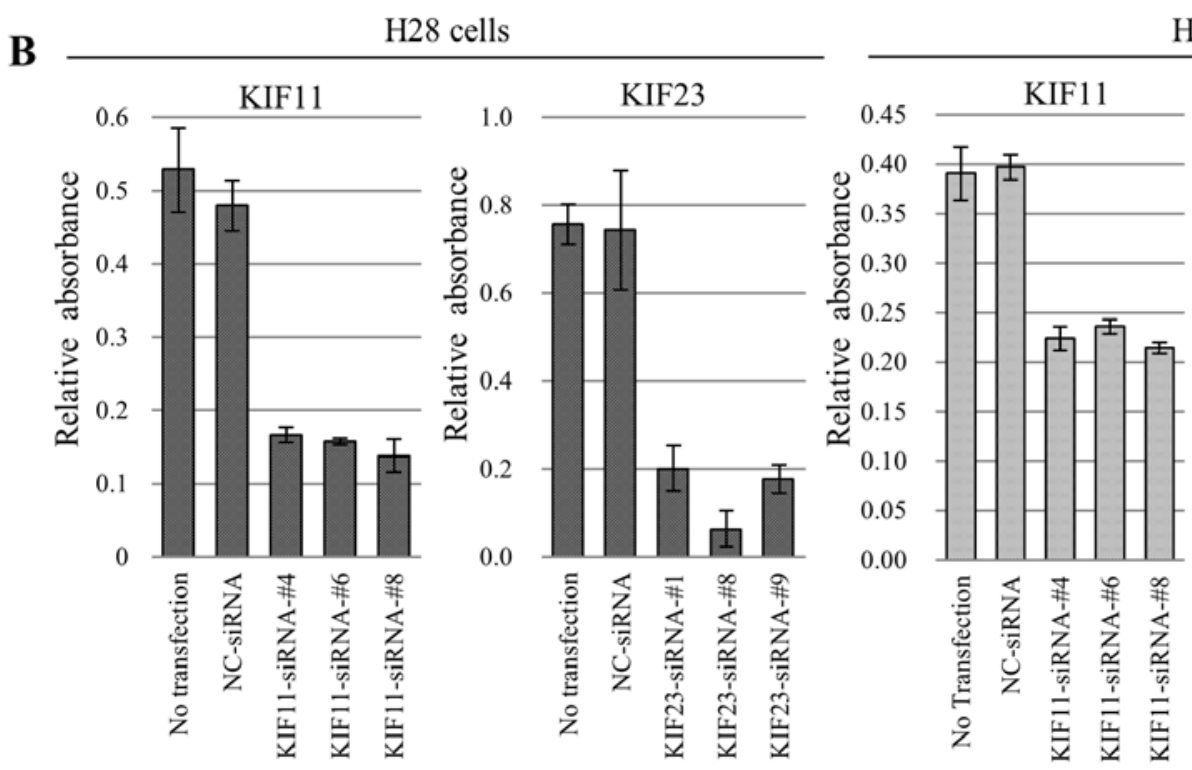

H2052 cells

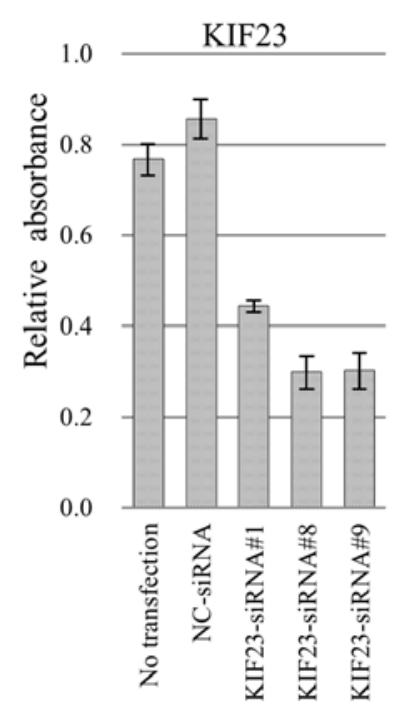

Figure 2. Effects of KIF11 and KIF23 short interfering RNA (siRNA) on human malignant mesothelioma cell proliferation in vitro. (A) Quantitative RT-PCR analysis of KIF11 and KIF23 expression in H28 and H2052 cells treated with negative control (NC) siRNA, and three different KIF11- and KIF23-specific siRNAs. Results shown are mean \pm SEM (bars) of duplicates. (B) Effects of KIF11 and KIF23 siRNAs on malignant mesothelioma cell proliferation in vitro: cells were treated with siRNAs for $96 \mathrm{~h}$, and cell viability was determined using a CellTiter96 ${ }^{\circledR}$ AQueous One Solution Cell Proliferation Assay. Results shown are mean $\pm \mathrm{SD}$ (bars) of three experiments.

shown). Analysis using the Kaplan-Meier method indicated significant associations between KIF23-H and MPM patients who received curative resection with KIF23-H had shorter overall 5-year survival than those with KIF23-L ( $\mathrm{P}=0.0194$, by a log-rank test; Fig. 3C). A similar trend was observed in KIF11 expression even though the difference was not statistically significant.

\section{Discussion}

Despite the availability of more advanced surgical techniques and adjuvant chemoradiotherapy, MPM still has poor prognosis compared to malignant tumors. Therefore, there is an urgent need to identify novel diagnostic biomarkers for early detection of cancer and to offer alternative or improved adjuvant treatment modalities to individual patients, as well as for developing new types of anticancer drugs and cancer vaccines. To investigate appropriate diagnostic and therapeutic target genes, we used a real-time RT-PCR and RNAi-based approach. Through the screening, we have identified several therapeutic candidate genes: PLK1, NDC80, KIF11 and KIF23 for MPM. An involvement in MPM cell growth and survival has already been demonstrated for PLK1 $(25,26)$ and NDC80 (26). Taken together, these observations support our RNAi-based screens to identify molecular targets in MPMs. In further characterizing candidate therapeutic targets, we focused on kinesin family members, KIF11 and KIF23, in the present study. 

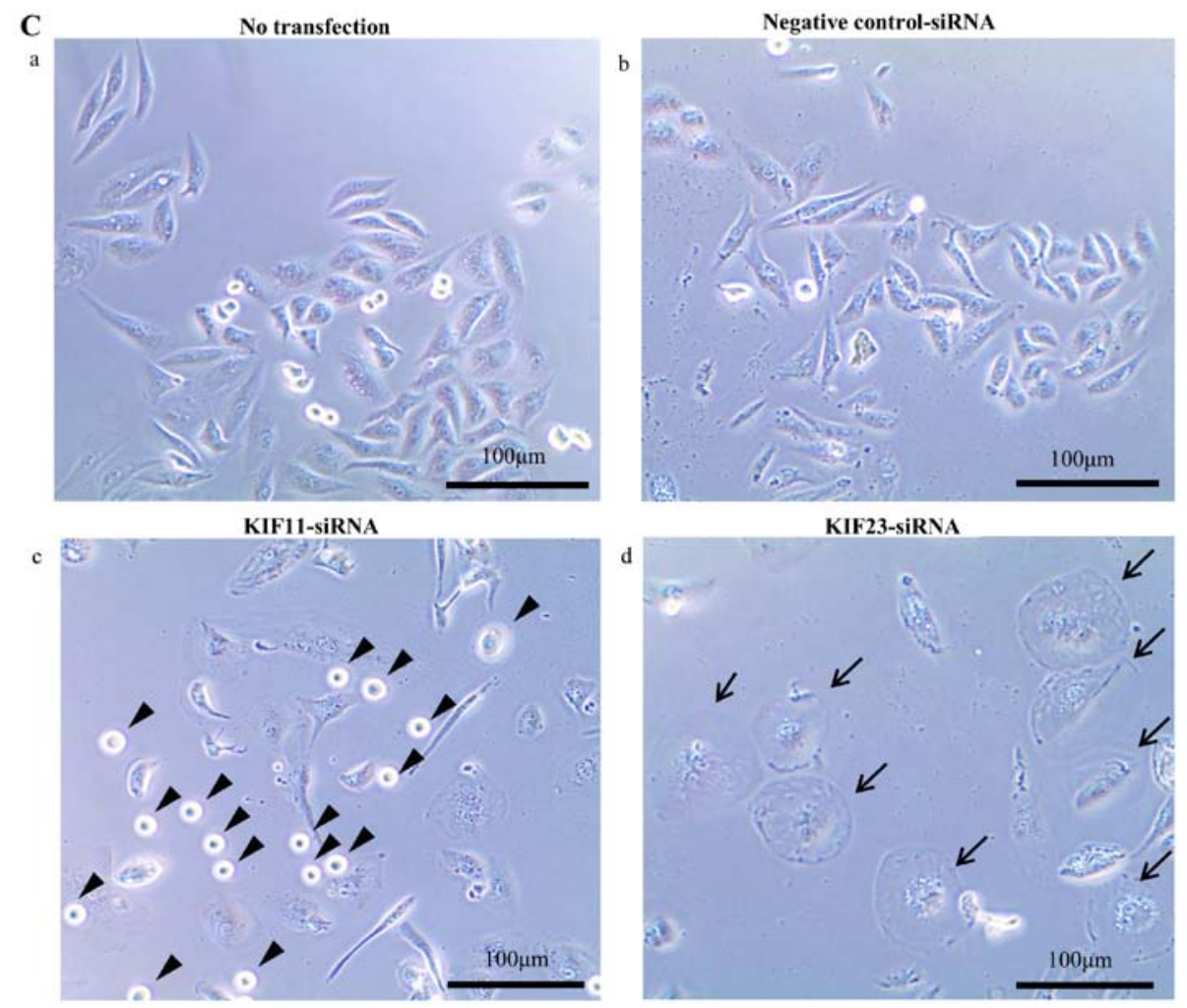

Figure 2. Continued. (C) Effect of KIF11 and KIF23 siRNAs on morphology (H28 human malignant mesothelioma cell line). Representative micrographs $52 \mathrm{~h}$ after siRNA treatments.

Table II. Immunopositivity of KIF11 and KIF23 protein in MPMs ( $\mathrm{n}=53)$.

\section{KIF11 expression}

\begin{tabular}{|c|c|c|c|c|c|c|}
\hline \multirow[b]{2}{*}{$\begin{array}{l}\text { Histology/ } \\
\text { IHC score }\end{array}$} & \multicolumn{2}{|c|}{ KIF11 low expression $(n=30)$} & \multicolumn{2}{|c|}{ KIF11 high expression $(n=23)$} & \multirow[b]{2}{*}{ Total (n) } & \multirow[b]{2}{*}{$\begin{array}{c}\% \text { of high } \\
\text { expression cases }\end{array}$} \\
\hline & $\begin{array}{c}\text { Negative } \\
\text { (IHC score, } \\
-0.299 \text { ) }\end{array}$ & $\begin{array}{c}\text { Weak } \\
\text { (IHC score, } \\
0.300-0.699 \text { ) }\end{array}$ & $\begin{array}{c}\text { Moderate } \\
\text { (IHC score, } \\
0.700-0.999 \text { ) }\end{array}$ & $\begin{array}{c}\text { Strong } \\
\text { (IHC score, } \\
1.000-)\end{array}$ & & \\
\hline Epithelioid & 5 & 13 & 10 & 6 & 34 & 47.1 \\
\hline Biphasic & 2 & 5 & 4 & 2 & 13 & 46.2 \\
\hline Sarcomatoid & 2 & 2 & 0 & 1 & 5 & 20.0 \\
\hline Desmoplastic & 1 & 0 & 0 & 0 & 1 & 0.0 \\
\hline Total & 10 & 20 & 14 & 9 & 53 & 43.4 \\
\hline
\end{tabular}

KIF23 expression

\begin{tabular}{|c|c|c|c|c|c|c|}
\hline \multirow[b]{2}{*}{ Histology } & \multicolumn{2}{|c|}{ KIF23 low expression $(n=26)$} & \multicolumn{2}{|c|}{ KIF23 high expression $(\mathrm{n}=27)$} & \multirow[b]{2}{*}{ Total (n) } & \multirow[b]{2}{*}{$\begin{array}{c}\% \text { of high } \\
\text { expression cases }\end{array}$} \\
\hline & $\begin{array}{c}\text { Negative } \\
\text { (IHC score, } \\
-0.199)\end{array}$ & $\begin{array}{c}\text { Weak } \\
\text { (IHC score, } \\
0.200-0.399 \text { ) }\end{array}$ & $\begin{array}{c}\text { Moderate } \\
\text { (IHC score, } \\
0.400-0.699 \text { ) }\end{array}$ & $\begin{array}{c}\text { Strong } \\
\text { (IHC score, } \\
0.700-\text { ) }\end{array}$ & & \\
\hline Epithelioid & 6 & 6 & 13 & 9 & 34 & 64.7 \\
\hline Biphasic & 3 & 5 & 4 & 1 & 13 & 38.5 \\
\hline Sarcomatoid & 1 & 4 & 0 & 0 & 5 & 0.0 \\
\hline Desmoplastic & 1 & 0 & 0 & 0 & 1 & 0.0 \\
\hline Total & 11 & 15 & 17 & 10 & 53 & 50.9 \\
\hline
\end{tabular}

IHC score, immunohistochemical score. 
A
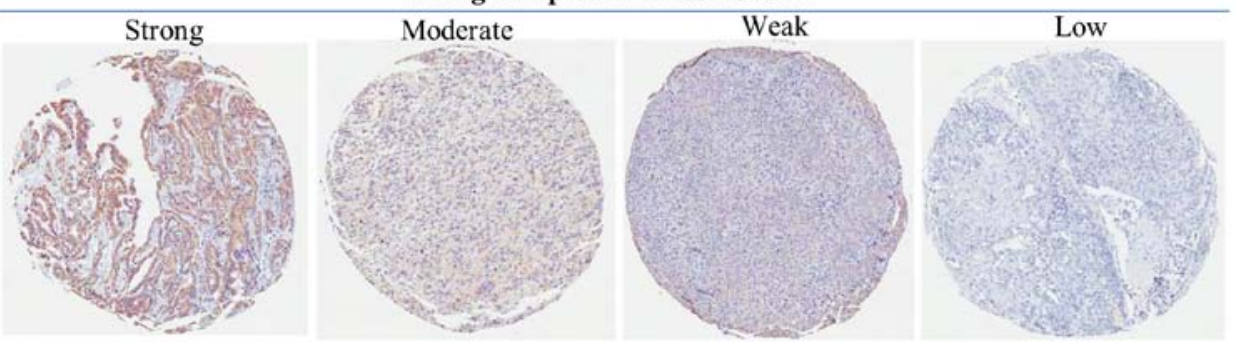

KIF11
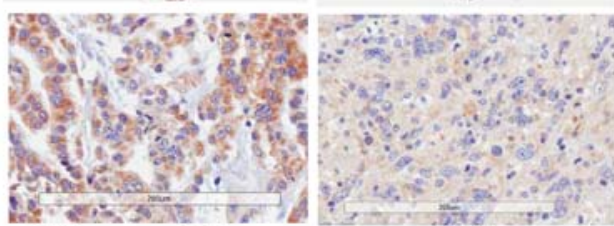

$\mathrm{IHC}$ score $=\mathbf{1 . 5 1}$

0.94
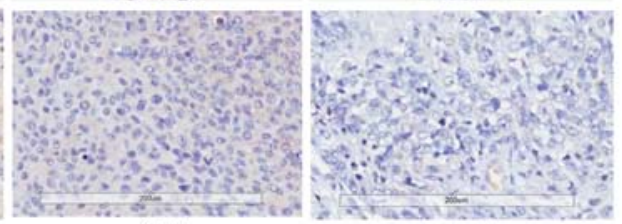

0.54

0.04

KIF23
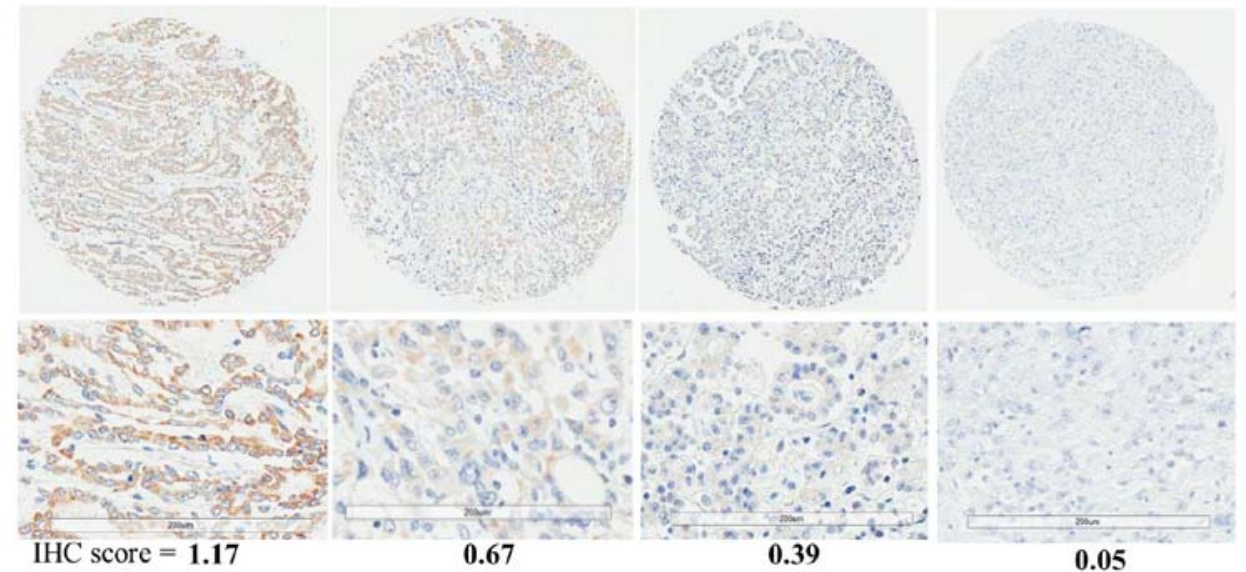

Benign lesion

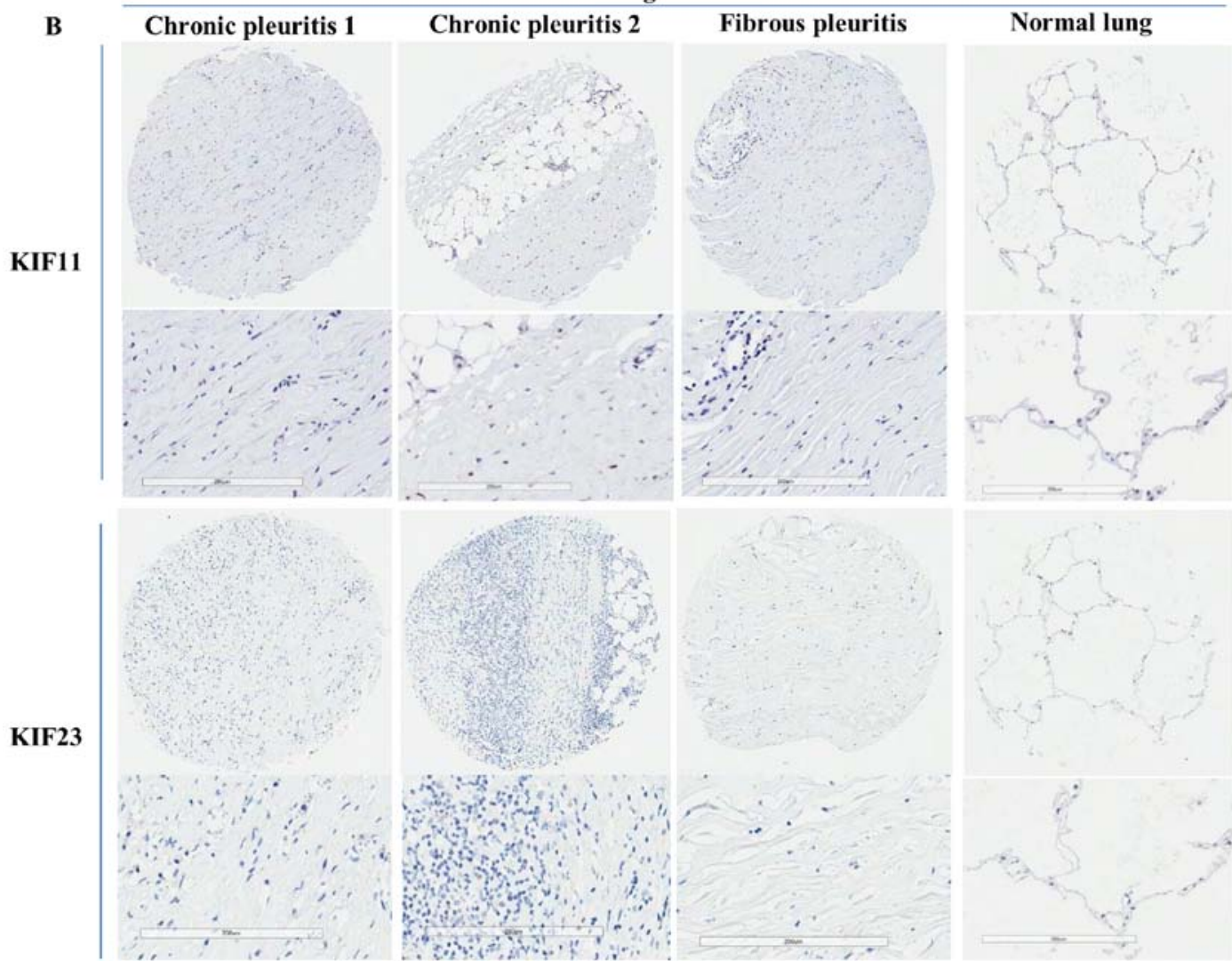

Figure 3. Staining patterns and intensities for KIF11 and KIF23 expression in MPM clinical samples and overall survival curves for MPM patients by IHC-score. (A) Representative examples of KIF11 and KIF23 protein expression in MPMs. Intensity and proportion were multiplied together to obtain the immunohistochemical (IHC) score (each score is indicated below the image). High to low expression of KIF11 (upper). High to low expression of KIF23 (lower). (B) No KIF11 and KIF23 immunohistochemical staining was observed in chronic pleuritis and normal lung tissue. 


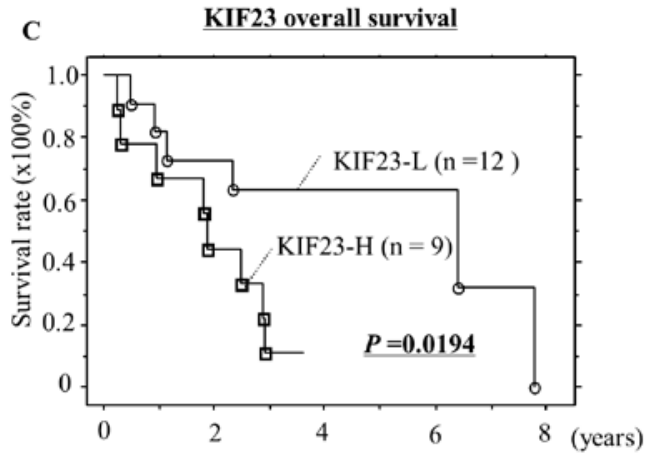

O KIF23-L (Low-level KIF23: IHC score $<0.4)$ KIF23-H (High-level KIF23: IHC score $\geq 0.4)$

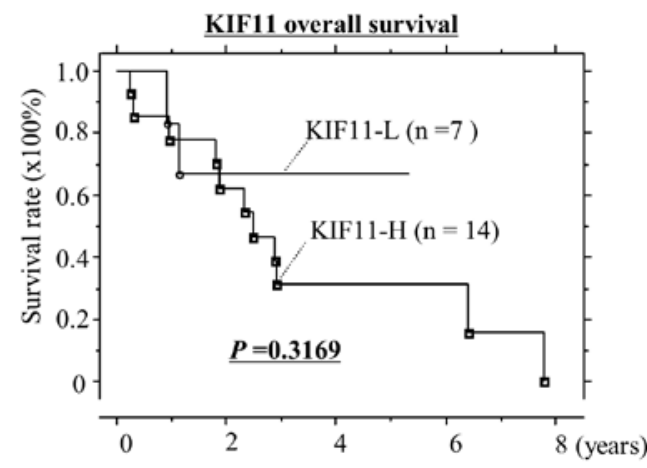

O KIF11-L (Low-level KIF11: IHC score $<0.7$ ) KIF11-H (High-level KIF11: IHC score $\geq 0.7)$

Figure 3. Continued. (C) Kaplan-Meier analysis of overall survival in MPM patients who received curative resection (EPP; extrapleural pleuropneumonectomy) according to KIF23 (left) and KIF11 expression level (right).

KIF11, a homotetramer motor protein belonging to the kinesin superfamily, was initially identified in Xenopus laevis and was shown to play an essential role in centrosome separation by cross-linking microtubules in the mitotic spindle (27-30). KIF11 was also identified as an important molecule during G2-M phase transition, underlining the importance of this cell cycle checkpoint for non-small cell lung cancer (NSCLC) and head and neck squamous cell carcinoma (HNSCC) cell survival (31). Overexpression of KIF11 has been associated with poor prognosis in various types of cancer $(32,33)$. A KIF11 inhibitor, monastrol, has been selected as an antimitotic agent using a phenotype-based screening (20). Monastrol prevents centrosome separation and generates a monoastral spindle phenotype as shown in our RNAi experiment (Fig. 2C), triggering mitotic arrest and eventual apoptosis (21). Recently, more potent monastrol-based compounds and other small molecules targeting the ATPase activity of KIF11 have been developed (34-41). Kinesin inhibitors have been shown to exhibit strong antitumor activity and many are currently undergoing clinical trials $(38,42,43)$. However, in spite of the important role KIF11 plays during cell proliferation, the significance of KIF11 transactivation in carcinogenesis and its potential as a prognostic biomarker of MPM is yet to be reported. Our findings suggest that the therapeutic value of KIF11 extends also to MPM.

KIF23, a human homolog of mouse Kif23, is a member of kinesin motor protein involved in the regulation of cytokinesis $(44,45)$. Suppression of KIF23 expression inhibits midbody formation and thus completion of cytokinesis (23). Previous studies have reported that inhibiting KIF23 induces the formation of binucleated/multinucleated cells because of a cytokinesis defect $(23,24)$. In the present study, we also confirmed this phenomenon in H28 human MPM cells (Fig. 2C). KIF23 overexpression is a common event seen in various tumors, such as glioma (22), breast (46), and paclitaxel-resistant gastric cancer (47). In addition, downregulating KIF23 expression significantly suppressed glioma cell proliferation both in vitro and in vivo (22). Importantly, high levels of the KIF23 mRNA are strongly associated with poor survival in patients with glioma and ER-positive breast cancer $(22,46)$. Although this result needs to be further validated using another set of TMA due to the small sample size in the present study, and intra-tumoral homogeneity of KIF23 expression should be indicated by whole section IHC, before correlating TMA-IHC data with survivals of each individual case, this study suggests a possibility that KIF23 overexpression offers a valuable prognostic factor in MPMs.

In conclusion, the present study demonstrates that a high level of KIF11 and KIF23 expression is observed in the majority of MPM clinical cases as well as several human mesothelioma cell lines. These two kinesin family member genes are crucial for the growth and survival of MPM cells. We also found that a high level of KIF23 is associated with poor survival. Thus, the results strongly suggest that these genes may have an important future role in identifying new therapeutic targets for MPMs.

\section{Acknowledgements}

The authors are especially thankful to Mr. Hiraku Shida (Tonan Hospital, Sapporo, Japan). The authors also thank Ms. Judy McConnell and Ms. Alexandria Grindlay (Toronto General Hospital) for laboratory management.

\section{References}

1. Yang H, Testa JR and Carbone M: Mesothelioma epidemiology, carcinogenesis, and pathogenesis. Curr Treat Options Oncol 9: 147-157, 2008.

2. Carbone M, Kratzke RA and Testa JR: The pathogenesis of mesothelioma. Semin Oncol 29: 2-17, 2002.

3. Travis WD, Brambilla E, Burke AP, Marx A and Nicholson AG: WHO Classification of Tumours of the Lung, Pleura, Thymus and Heart. In: WHO Classification of Tumours. Vol. 7. 4th edition. IARC Press, Lyon, 2015.

4. Robinson BW and Lake RA: Advances in malignant mesothelioma. N Engl J Med 353: 1591-1603, 2005.

5. Robinson BW, Musk AW and Lake RA: Malignant mesothelioma. Lancet 366: 397-408, 2005.

6. Becklake MR, Bagatin E and Neder JA: Asbestos-related diseases of the lungs and pleura: Uses, trends and management over the last century. Int J Tuberc Lung Dis 11: 356-369, 2007.

7. Vogelzang NJ, Rusthoven JJ, Symanowski J, Denham C, Kaukel E, Ruffie P, Gatzemeier U, Boyer M, Emri S, Manegold C, et al: Phase III study of pemetrexed in combination with cisplatin versus cisplatin alone in patients with malignant pleural mesothelioma. J Clin Oncol 21: 2636-2644, 2003.

8. Zucali PA, De Vincenzo F, Simonelli M and Santoro A: Future developments in the management of malignant pleural mesothelioma. Expert Rev Anticancer Ther 9: 453-467, 2009. 
9. Kato T, Wada H, Patel P, Hu S, Lee D, Hirohashi K, Nakajima T, Kaji M, Kaga K, Matsui Y, et al: Overexpression of KIF23 predicts clinical outcome in primary lung cancer patients. Lung Cancer 92: 53-61, 2016.

10. NCBI: Gene. http://www.ncbi.nlm.nih.gov/gene.

11. Science WIo: GeneCards. v4.0 Build 17. http://www.genecards. org/.

12. Schmidt E: GenomeRNAi. 2013. http://genomernai.dkfz.de/ GenomeRNAi//.

13. Research LIfC: CTDatabase. http://www.cta.lncc.br/.

14. Sobin LH, Gospodarowicz MK and Wittekind C: Union for International Cancer Control (UICC), TNM Classification of Malignant Tumours. 7th edition. Wiley-Blackwell, New York, 2009.

15. Nakajima T, Anayama T, Koike T, Waddell T, Keshavjee S, Kimura H, Yoshino I and Yasufuku K: Simultaneous isolation of total RNA, DNA, and protein using samples obtained by EBUSTBNA. J Bronchology Interv Pulmonol 18: 301-305, 2011.

16. Nakajima T, Zamel R, Anayama T, Kimura H, Yoshino I, Keshavjee S and Yasufuku K: Ribonucleic acid microarray analysis from lymph node samples obtained by endobronchial ultrasonography-guided transbronchial needle aspiration. Ann Thorac Surg 94: 2097-2101, 2012.

17. Rizzardi AE, Johnson AT, Vogel RI, Pambuccian SE, Henriksen J, Skubitz AP, Metzger GJ and Schmechel SC: Quantitative comparison of immunohistochemical staining measured by digital image analysis versus pathologist visual scoring. Diagn Pathol 7: 42, 2012

18. Nagashio R, Sato Y, Jiang SX, Ryuge S, Kodera Y, Maeda T and Nakajima T: Detection of tumor-specific autoantibodies in sera of patients with lung cancer. Lung Cancer 62: 364-373, 2008.

19. Nagashio R, Sato Y, Matsumoto T, Kageyama T, Satoh Y, Shinichiro R, Masuda N, Goshima N, Jiang SX and Okayasu I: Expression of RACK1 is a novel biomarker in pulmonary adenocarcinomas. Lung Cancer 69: 54-59, 2010.

20. Mayer TU, Kapoor TM, Haggarty SJ, King RW, Schreiber SL and Mitchison TJ: Small molecule inhibitor of mitotic spindle bipolarity identified in a phenotype-based screen. Science 286 : 971-974, 1999.

21. Kapoor TM, Mayer TU, Coughlin ML and Mitchison TJ: Probing spindle assembly mechanisms with monastrol, a small molecule inhibitor of the mitotic kinesin, Eg5. J Cell Biol 150: 975-988, 2000.

22. Takahashi S, Fusaki N, Ohta S, Iwahori Y, Iizuka Y, Inagawa K, Kawakami Y, Yoshida K and Toda M: Downregulation of KIF23 suppresses glioma proliferation. J Neurooncol 106: 519-529, 2012.

23. Zhu C, Bossy-Wetzel E and Jiang W: Recruitment of MKLP1 to the spindle midzone/midbody by INCENP is essential for midbody formation and completion of cytokinesis in human cells. Biochem J 389: 373-381, 2005.

24. Liu X, Zhou T, Kuriyama R and Erikson RL: Molecular interactions of Polo-like-kinase 1 with the mitotic kinesin-like protein CHO1/MKLP-1. J Cell Sci 117: 3233-3246, 2004.

25. Kawata E, Ashihara E, Nakagawa Y, Kiuchi T, Ogura M, Yao H, Sakai K, Tanaka R, Nagao R, Yokota A, et al: A combination of a DNA-chimera siRNA against PLK-1 and zoledronic acid suppresses the growth of malignant mesothelioma cells in vitro. Cancer Lett 294: 245-253, 2010.

26. Linton A, Cheng YY, Griggs K, Kirschner MB, Gattani S, Srikaran S, Chuan-Hao Kao S, McCaughan BC, Klebe S, van Zandwijk N, et al: An RNAi-based screen reveals PLK1, CDK1 and NDC80 as potential therapeutic targets in malignant pleural mesothelioma. Br J Cancer 110: 510-519, 2014

27. Le Guellec R, Paris J, Couturier A, Roghi C and Philippe M: Cloning by differential screening of a Xenopus cDNA that encodes a kinesin-related protein. Mol Cell Biol 11: 3395-3398, 1991.

28. Sawin KE, LeGuellec K, Philippe M and Mitchison TJ: Mitotic spindle organization by a plus-end-directed microtubule motor. Nature 359: 540-543, 1992.

29. Sawin KE and Mitchison TJ: Mutations in the kinesin-like protein Eg5 disrupting localization to the mitotic spindle. Proc Natl Acad Sci USA 92: 4289-4293, 1995.

30. Blangy A, Lane HA, d'Hérin P, Harper M, Kress M and Nigg EA Phosphorylation by $\mathrm{p} 34 \mathrm{cdc} 2$ regulates spindle association of human Eg5, a kinesin-related motor essential for bipolar spindle formation in vivo. Cell 83: 1159-1169, 1995.
31. Martens-de Kemp SR, Nagel R, Stigter-van Walsum M, van der Meulen IH, van Beusechem VW, Braakhuis BJ and Brakenhoff RH: Functional genetic screens identify genes essential for tumor cell survival in head and neck and lung cancer. Clin Cancer Res 19: 1994-2003, 2013.

32. Ding S, Xing N, Lu J, Zhang H, Nishizawa K, Liu S, Yuan X, Qin Y, Liu Y, Ogawa O, et al: Overexpression of Eg5 predicts unfavorable prognosis in non-muscle invasive bladder urothelial carcinoma. Int J Urol 18: 432-438, 2011

33. Sun D, Lu J, Ding K, Bi D, Niu Z, Cao Q, Zhang J and Ding S: The expression of Eg5 predicts a poor outcome for patients with renal cell carcinoma. Med Oncol 30: 476, 2013.

34. Vijapurkar U, Wang W and Herbst R: Potentiation of kinesin spindle protein inhibitor-induced cell death by modulation of mitochondrial and death receptor apoptotic pathways. Cancer Res 67: 237-245, 2007.

35. Garcia-Saez I, DeBonis S, Lopez R, Trucco F, Rousseau B, Thuéry P and Kozielski F: Structure of human Eg5 in complex with a new monastrol-based inhibitor bound in the R configuration. J Biol Chem 282: 9740-9747, 2007.

36. Luo L, Parrish CA, Nevins N, McNulty DE, Chaudhari AM, Carson JD, Sudakin V, Shaw AN, Lehr R, Zhao H, et al: ATP-competitive inhibitors of the mitotic kinesin KSP that function via an allosteric mechanism. Nat Chem Biol 3: 722-726, 2007.

37. Brier S, Lemaire D, Debonis S, Forest E and Kozielski F: Identification of the protein binding region of S-trityl-L-cysteine, a new potent inhibitor of the mitotic kinesin Eg5. Biochemistry 43: 13072-13082, 2004.

38. Sakowicz R, Finer JT, Beraud C, Crompton A, Lewis E, Fritsch A, Lee Y, Mak J, Moody R, Turincio R, et al: Antitumor activity of a kinesin inhibitor. Cancer Res 64: 3276-3280, 2004.

39. Lad L, Luo L, Carson JD, Wood KW, Hartman JJ, Copeland RA and Sakowicz R: Mechanism of inhibition of human KSP by ispinesib. Biochemistry 47: 3576-3585, 2008.

40. Cox CD, Coleman PJ, Breslin MJ, Whitman DB, Garbaccio RM, Fraley ME, Buser CA, Walsh ES, Hamilton K, Schaber MD, et al: Kinesin spindle protein (KSP) inhibitors. 9. Discovery of (2S)-4-(2,5-difluorophenyl)- $N$-[(3R,4S)-3-fluoro-1-methylpiperidin-4-yl]-2-(hydroxymethyl)- $N$-methyl-2-phenyl-2,5dihydro-1 $H$-pyrrole-1-carboxamide (MK-0731) for the treatment of taxane-refractory cancer. J Med Chem 51: 4239-4252, 2008.

41. TheoclitouME,AquilaB,BlockMH,BrassilPJ,CastriottaL,CodeE, Collins MP, Davies AM, Deegan T, Ezhuthachan J, et al: Discovery of (+)- $N$-(3-aminopropyl)- $N$-[1-(5-benzyl-3-methyl-4-oxo-[1,2] thiazolo[5,4-d]pyrimidin-6-yl)-2-methylpropyl]-4-methylbenzamide (AZD4877), a kinesin spindle protein inhibitor and potential anticancer agent. J Med Chem 54: 6734-6750, 2011.

42. Souid AK, Dubowy RL, Ingle AM, Conlan MG, Sun J, Blaney SM and Adamson PC: A pediatric phase I trial and pharmacokinetic study of ispinesib: A Children's Oncology Group phase I consortium study. Pediatr Blood Cancer 55: 1323-1328, 2010.

43. Infante JR, Kurzrock R, Spratlin J, Burris HA, Eckhardt SG Li J, Wu K, Skolnik JM, Hylander-Gans L, Osmukhina A, et al: A Phase I study to assess the safety, tolerability, and pharmacokinetics of AZD4877, an intravenous Eg5 inhibitor in patients with advanced solid tumors. Cancer Chemother Pharmacol 69: 165-172, 2012.

44. Glotzer M: The molecular requirements for cytokinesis. Science 307: 1735-1739, 2005

45. Neef R, Klein UR, Kopajtich R and Barr FA: Cooperation between mitotic kinesins controls the late stages of cytokinesis. Curr Biol 16: 301-307, 2006.

46. Zou JX, Duan Z, Wang J, Sokolov A, Xu J, Chen CZ, Li JJ and Chen HW: Kinesin family deregulation coordinated by bromodomain protein ANCCA and histone methyltransferase MLL for breast cancer cell growth, survival, and tamoxifen resistance. Mol Cancer Res 12: 539-549, 2014.

47. Murakami H, Ito S, Tanaka H, Kondo E, Kodera $\mathrm{Y}$ and Nakanishi H: Establishment of new intraperitoneal paclitaxelresistant gastric cancer cell lines and comprehensive gene expression analysis. Anticancer Res 33: 4299-4307, 2013. 